\title{
XXXVI. The high-frequency spectrum of tungsten
}

\section{James Barnes Ph.D.}

To cite this article: James Barnes Ph.D. (1915) XXXVI. The high-frequency spectrum of tungsten, Philosophical Magazine Series 6, 30:177, 368-370, DOI: 10.1080/14786440908635407

To link to this article: http://dx.doi.org/10.1080/14786440908635407

曲 Published online: 08 Apr 2009.

Submit your article to this journal

Џ Article views: 5

Q View related articles $\sqsubset$

4 Citing articles: 2 View citing articles 
XXXVI. The High-Frequency Spectrum of T'ungsten. B'y James Barnes, Ph.D., Research Fellow, Linicersity of Manchester *.

THE investigation of the high-frequency spectrum of the $1 \mathrm{X}$ rays coming from a Coolidge tube with a tungsten anticathode was thought to be of interest in connexion with the accompanying paper + . The method used for obtaining and photographing the spectrum was the same as that employed by Moseley $\ddagger$. The crystal was placed on a goniometer table and adjusted so that the face upon which the rays were incident passed through the axis of rotation. The beam of rays coming through the slit of about $0.5 \mathrm{~mm}$. width was intersected by the axis and fell approximately on the centre of the face of the crystal. The perpendicular distance from the axis to the photographic plate was $20.12 \mathrm{~cm}$., and the distance from the slit to the axis was made as near as possible the same. The crystal was kept throughout the exposure in slow rotation by the method used by Professor Rutherford and Dr. Andrade $\S$ in their determination of the spectrum of the soft gamma rays from radium $B$.

The lines were first photographed on one side of the central image of the slit, then the crystal was turned through $180^{\circ}$ and the lines obtained on the other side. The so-called reflexion angle $\theta$ can then be calculated from the expression

$$
2 \theta=\tan ^{-1} \frac{a}{40 \cdot 24}
$$

where $a$ is the distance between like lines on the same plate. The longest time of exposure employed was six hours. Satisfactory photographs of the strongest lines in the " $L$ " series could easily be got in half an hour. The glass wall of the bulb being $0.5 \mathrm{~mm}$. thick, at least one-fiftieth of the intensity of this soft radiation is absorbed by the glass. With a bulb having a side tube with its end covered with thin aluminium, good photographs of this series would probably be obtained in a few minutes under similar conditions.

The following table contains the results obtained with a rock-salt crystal, $1 \cdot 6 \mathrm{~cm}$. thick, whose face was $3 \cdot 5 \times 1.9 \mathrm{~cm}$.

\footnotetext{
* Communicated by Sir Ernest Rutherford, F.R.S.

† Phil. Mag. suprà, p. 339.

+ Phil. Mag. xxvii. p. 703 (1914).

\$ Phil. Mag. xxvii. p. 858 (1914).
} 
The reflexion angles are believed to be accurate within \pm 3 '. The wave-lengths are calculated from the formula

$$
\lambda=2 d \sin \theta,
$$

where $d$ is taken as $2.814 \times 10^{-8} \mathrm{~cm}$.

\begin{tabular}{|c|c|l|}
\hline Reflexion angle. & Ware-lengths $\times 10^{y} \mathrm{~cm}$. & Intensity. \\
\hline $15^{\circ} 13^{\prime}$ & 1.477 & Strong. \\
$13^{\circ} 29^{\prime}$ & 1.312 & Weak. \\
$13^{\circ} 19^{\prime}$ & 1.296 & Strong. \\
$13^{\circ} 07^{\prime}$ & 1.277 & Weak. \\
$12^{\circ} 55^{\prime}$ & 1.258 & Strong. \\
$11^{\circ} 24^{\prime}$ & 1.113 & Stroug. \\
$11^{\circ} 05^{\prime}$ & 1.082 & Weak. \\
\hline
\end{tabular}

It will be noticed from this table that the first line corresponds to the only line in the spectrum of tungsten referred to by Moseley, which he designates the a line of the " $L$ " series. The lines $\lambda 1.296$ and $\lambda 1.258$ fill exactly the gaps in the curves as given by the beta and gamma lines of this series for the elements from zirconium to gold. $\lambda 1.277$ is probably the $\phi$ radiation. It will be interesting to investigate if these elements have also radiations analogous to $\lambda 1 \cdot 312, \lambda 1 \cdot 113$, and $\lambda 1 \cdot 082$.

Extrapolating Moseley's * results as expressed by the relation

$$
\nu=\mathrm{C}(\mathrm{N}-1)^{2},
$$

where $\nu$ is the frequency, $\mathrm{C}$ a constant, and $\mathrm{N}$ the atomic number, which for tungsten is 74 , we get $0.22 \times 10^{-8} \mathrm{~cm}$. for the wave-length of the a line of the " $\mathrm{K}$ " series. This wave-length corresponds to a reflexion angle of $2^{\circ} 18^{\prime}$ from rock-salt. The photographs obtained with the thick crystal showed no signs of this line, but a continuous spectrum extended from $4^{\circ} 54^{\prime}$ almost to the edge of the central image. Beyond this band towards the longer wave-lengths was another band much less uniform in intensity, and extending almost to the lines of the "L" series. De Broglie + found similar results for tungsten and platinum (atomic number 78); and Malmer $\ddagger$ observed in the case of cerium

\footnotetext{
* Phil. Mag. xxvii. p. 710 (1914).

† Comptes Rendus, clviii. p. 177 (1914).

$\ddagger$ Phil. Mag. xxviii. p. 792 (1914).
}

Phil. Mag. S. 6. Vol. 30. No. 177. Sept. 1915. 
(atomic number 58) a continuous spectrum in the place where the lines of the " $\mathrm{K}$ " series should appear. It was thought that possibly the spectrum of this series might consist of a large number of lines which blended into one another, giving the appearance of a continuous spectrum and due to the layers of the crystal not being accurately enough spaced for these short radiations. The penetrating power of these radiations being so great, every layer in the thick crystal is almost equally active, while for the " $\mathrm{L}$ " series, most of the reflexion comes from the planes in the first millimetre. A number of thin rock-salt crystals about one millimetre thick were then used, with the result that the bands were not nearly so uniform in intensity as in the photographs with the thick crystal. The lines were broad and diffuse, and many were wavy, so that measurements of any accuracy were impossible. In any case, there were no clearly marked characteristics of the " $K$ " series, even when the maximum potertial on the bulb was 100,000 volts. According to Planck's relation, $\mathrm{E}=h \nu$, the a line should appear when the electrons have the energy of approximately 58,000 volts, while according to the observations in the accompanying paper, this characteristic if present should appear at 74,000 volts. These spectroscopic observations, therefore, agree with the absorption results, the curves of which showed no evidence of being able to be resolved into a fow exponentials representing characteristic radiations.

In conclusion, the author wishes to express his best thanks to Sir Ernest Rutherford for many suggestions in the course of the above observations, and also for the privilege of working in his laboratory.

XXXVII. On Mutual Electromagnetic Mass. By L. SILBEksteIn, Ph.D., Lecturer in Natural Philosophy at the University of Rome *

THE electromagnetic mass of a system of two charges, $e_{1}$ and $e_{2}$, is of the form

$$
m_{1}+m_{2}+m_{12}
$$

where $m_{1}, m_{2}$ are determined by the shape and size of, and the distribution of electricity in, 1 and 2, respectively; whereas $m_{12}$ depends on the mutual relations of the two charged regions to one nnother. The first two terms of the above sum being called the masses of 1 and 2 , respectively,

* Communicated by the Author. 